\title{
Impedance study on the capacitance of silver electrode oxidised in alkaline electrolyte
}

\author{
M. Grdeń ${ }^{1}$
}

Received: 6 May 2017 / Revised: 17 June 2017 / Accepted: 19 June 2017 / Published online: 3 July 2017

(C) The Author(s) 2017. This article is an open access publication

\begin{abstract}
Electrochemical properties of oxide-covered polycrystalline Ag electrodes were studied in a $0.1 \mathrm{M} \mathrm{KOH}$ aqueous electrolyte. The oxide layers formed by a constant potential oxidation at $420 \mathrm{mV}$ vs. $\mathrm{Hg} \mid \mathrm{HgO}$ are composed of oxygen-deficient $\mathrm{Ag}_{2} \mathrm{O}$ as follows from the XPS and Auger experiments. Steady-state conditions required for collection of valid impedance spectra were obtained at a potential range of 345-365 mV. The components of the equivalent circuit used for the impedance spectra analysis are analysed as a function of the $\mathrm{Ag}_{2} \mathrm{O}$ layer thickness. The value of the coefficient of the constant phase element (CPE) attributed to the oxide layer is $\mathrm{Ag}_{2} \mathrm{O}$ thickness dependent. On the other hand, the components of the CPE describing the double-layer capacitance of the oxide-covered $\mathrm{Ag}$ electrode are independent on the oxide thickness and their values are comparable to those obtained for the oxide-free metal. This indicates that the double-layer capacitances of oxide-covered and oxide-free Ag electrodes are similar.
\end{abstract}

Keywords Silver $\cdot$ Silver oxidation $\cdot \mathrm{Ag}_{2} \mathrm{O} \cdot$ Double layer . Capacitance

Electronic supplementary material The online version of this article (doi:10.1007/s10008-017-3684-2) contains supplementary material, which is available to authorized users.

M. Grdeń

mgrden@chem.uw.edu.pl

1 Faculty of Chemistry, Biological and Chemical Research Centre, University of Warsaw, Żwirki i Wigury 101, 02-089 Warsaw, Poland

\section{Introduction}

Measurements of the double-layer capacitance, $C_{\mathrm{dl}}$, are amongst the most important ways to study electrolyteelectrode interfaces in electrochemical systems. Analysis of the capacitance data is relatively simple for metallic electrodes but becomes complicated when the electrode is covered with a layer of an oxide/hydroxide. This is due to the fact that the most of the metal oxides and hydroxides exhibit non-metallic, i.e. semiconducting or insulating, properties [1,2]. The capacitance of a semiconducting oxide/hydroxide layer, $C_{\mathrm{ox}}$, contributes to the total measured interfacial capacitance of the electrolyte-electrode interface, $C_{\text {tot }}$, according to Eq. 1 [3-5]:

$C_{\mathrm{tot}}^{-1}=C_{\text {dlox }}^{-1}+C_{\mathrm{ox}}^{-1}$

where $C_{\mathrm{dlox}}$ stands for the double-layer capacitance of an oxide/hydroxide-covered electrode. The separate determination of $C_{\mathrm{dlox}}$ and $C_{\mathrm{ox}}$ values can be difficult, and it is often assumed that the $C_{\mathrm{dlox}}$ has the same value as $C_{\mathrm{dl}}$ of the oxidefree metallic surfaces, $C_{\mathrm{dlm}}[6]$. However, a strong deviation of experimentally determined $C_{\mathrm{dlox}}$ values from the typical range of $C_{\mathrm{dlm}}$ is often reported [e.g. 7, 8].

Silver is one of the metals with reported significant differences between $C_{\mathrm{dlm}}$ and $C_{\mathrm{dlox}}$ [8-10]. The double-layer capacitance of various types of Ag electrodes was studied in aqueous electrolytes at potentials where the surface is metallic [e.g. 11-17] and oxide-covered [8-10, 13, 15, 16, 18-20]. Silver oxidation in an alkaline electrolyte starts at ca. $10 \mathrm{mV}$ vs. $\mathrm{Hg} \mid \mathrm{HgO}$; the usually reported oxidation products are $\mathrm{Ag}_{2} \mathrm{O}$ and $\mathrm{AgO}$, depending on the oxidation potential [21-38]. $\mathrm{AgO}$ is described as a mixture of $\mathrm{Ag}(\mathrm{I})$ and $\mathrm{Ag}(\mathrm{III})$ species $[11,39,40]$. Ag oxides exhibit non-metallic properties, and this factor undoubtedly complicates determination of $C_{\mathrm{dlox}}$ (Eq. 2). Most of the authors point out to n-type 
semiconducting properties of the electrochemically formed $\mathrm{Ag}_{2} \mathrm{O}[1,21,41-44]$ although a p-type semiconductivity is also reported [21, 45, 46].

Hepel and Tomkiewicz [9] studied oxidised layers generated on $\mathrm{Ag}$ electrodes in $1 \mathrm{M} \mathrm{KOH}_{\mathrm{aq}}$ at potentials where $\mathrm{Ag}_{2} \mathrm{O}$ and $\mathrm{AgO}$ are formed. The oxides were formed during constant potential anodic oxidation of Ag while the interfacial capacitance was calculated on the basis of the high-frequency imaginary part of the impedance and was analysed as a function of the charge passed during formation of the oxide layer, $q_{\mathrm{ox}}$. The latter value was assumed to be a direct indicator of the oxide layer thickness, $l_{\mathrm{ox}}$. The analysis was based on a parallel plate capacitor approach (Eq. 2) [9]:

$C_{\mathrm{ox}}=\frac{\varepsilon_{\mathrm{r}} \varepsilon_{0} A}{l_{\mathrm{ox}}}$

where $A, \varepsilon_{\mathrm{r}}$ and $\varepsilon_{0}$ stand for the surface area and the relative permittivity of the oxidised layer and dielectric permittivity of the vacuum, respectively. $C_{\mathrm{dlox}}$ values, which were obtained from a combination of Eqs. (1) and (2), were in the range of $0.1 \mu \mathrm{F} \mathrm{cm}^{-2}$ [9] being substantially lower than tens of $\mu \mathrm{F} \mathrm{cm}{ }^{-2}$ typically reported for $C_{\mathrm{dlm}}$. It follows from data reported in [9] that for such low values of $C_{\mathrm{dlox}}$, the condition of $C_{\mathrm{ox}} \ll C_{\mathrm{dlox}}$ holds only for very thick oxide layers (oxidation charge of at least few hundred $\mathrm{mC} \mathrm{cm}^{-2}$ ).

In [8], the $C_{\mathrm{dlox}}$ of $\mathrm{Ag}$ electrodes oxidised in $1-10 \mathrm{M} \mathrm{KOH}$ was determined by means of extrapolation of a singlefrequency capacitance to the infinite-frequency limit. Such determined $C_{\text {dlox }}$ was dependent on the $\mathrm{Ag}_{2} \mathrm{O}$ layer thickness: for a monolayer film, its value was equal to ca. $50 \%$ of reported $C_{\mathrm{dlm}}\left(\sim 27 \mu \mathrm{F} \mathrm{cm}{ }^{-2}\right)$ while for a multilayer $\mathrm{Ag}_{2} \mathrm{O}$, the $C_{\mathrm{dlox}}$ was ca. order of magnitude smaller than $C_{\mathrm{dlm}}\left(10^{0} \mu \mathrm{F} \mathrm{cm} \mathrm{cm}^{-2}\right.$ range) [8]. In [10], several equivalent circuits were used in an analysis of the impedance data recorded for Ag oxidised in $\mathrm{KOH}_{\mathrm{aq}}$ at various potentials. The interfacial capacitance, identified as the double-layer capacitance of the oxide-electrolyte interface, was found to decrease upon the surface oxidation, even by two orders of magnitude to the $10^{0}-10^{-1} \mu \mathrm{F} \mathrm{cm}{ }^{-2}$ range [10]. The contribution from $C_{\mathrm{ox}}$ to the measured impedance was, however, not discussed. A decrease of the interfacial capacitance of $\mathrm{Ag}$ upon oxidation in $0.1 \mathrm{M} \mathrm{NaOH}$ was shown also in [15]. Measurements carried out at $\mathrm{pH}$ of 4.5 show that the overall capacitance measured with $370 \mathrm{~Hz}$ decreases with the polarisation time at potentials of phase oxide formation and oxygen chemisorption [16]. At such lowfrequency values, however, the contribution from pseudocapacitances can be significant [16].

An equivalent circuit containing two connected in series subcircuits, each of them composed with a parallel combination of a resistance and a capacitance $\left(C_{\mathrm{ox}}\right.$ or $\left.C_{\mathrm{dlox}}\right)$, was used for fitting impedance spectra for $\mathrm{Ag}$ oxides formed in $1 \mathrm{M} \mathrm{NaOH}$ in [41] and in $1 \mathrm{M} \mathrm{KOH}$ in [47]. Fast Fourier transform impedance spectroscopy [48] was applied in both these works; in [41], the spectra were recorded during a negative potential scan. The validity of the spectra recorded in [41] was evaluated by means of an analysis of the relation between power spectra of the perturbation signal and the recorded current [41]. The following $C_{\mathrm{ox}}$ values were obtained at potentials of $\mathrm{Ag}_{2} \mathrm{O}$ formation: ca. $0.6-9.7 \mu \mathrm{F} \mathrm{cm}^{-2}$ at ca. $330-600 \mathrm{mV}$ vs. $\mathrm{Hg} \mid \mathrm{HgO}$ in [47] and ca. $0.16-1.6 \mu \mathrm{F}$ at $100-290 \mathrm{mV}$ vs. SCE in [41] (the values of the double-layer capacitance were not reported). Considering the electrode diameter of $0.7 \mathrm{~cm}$ reported in [41], one may recalculate $C_{\mathrm{ox}}$ values from [41] into the specific capacitance range of ca. $0.4-4 \mu \mathrm{F} \mathrm{cm}^{-2}$ (in respect to the geometric area). When these $C_{\text {ox }}$ values from [41, 47] are compared with very low values of $C_{\text {dlox }}$ reported for $\mathrm{Ag}_{2} \mathrm{O}$-covered silver by other authors $\left(10^{0}-10^{-1} \mu \mathrm{F} \mathrm{cm}{ }^{-2}\right.$ range $\left.[9,10]\right)$, one may conclude that the requirement of $C_{\mathrm{dlox}} \gg C_{\mathrm{ox}}$ may not be met here, similarly as for data from [9]. Consequently, classical Mott-Schottky analysis of semiconducting electrodes which is based on the abovementioned relation between $C_{\mathrm{dlox}}$ and $C_{\mathrm{ox}}$ [3-5, 49-51] may be not applicable here. Clearly, the values of $C_{\mathrm{ox}}, C_{\mathrm{dlox}}$ and $C_{\mathrm{dlm}}$ need to be unequivocally determined and the relation between them has to be clarified if they are to be applied in a further analysis of the capacitance data.

This manuscript presents results of the studies on properties of $\mathrm{Ag}$ oxides formed electrochemically at the surface of a polycrystalline $\mathrm{Ag}$ in an alkaline electrolyte during constant potential oxidation at $420 \mathrm{mV}$ vs. $\mathrm{Hg} \mid \mathrm{HgO}$. Chemical composition of the oxidised layers was analysed by means of X-ray photoelectron spectroscopy (XPS) while electrochemical impedance measurements were applied to evaluate electrochemical properties of the interface between the electrolyte and the oxides studied. The impedance data are analysed as a function of the amount of generated Ag oxide, and the conclusions about the double-layer capacitance of the oxide-covered silver electrode are drawn.

\section{Experimental}

A silver wire or foil (4N, Mint of Poland) was used as a working electrode while a high surface area $\mathrm{Au}$ foil or $\mathrm{Pt}$ gauze wire and a $\mathrm{Hg} \mid \mathrm{HgO}(0.1 \mathrm{M} \mathrm{KOH})$ electrode served as counter and reference electrodes, respectively. Before the experiments, the silver electrode was cleaned by mechanical polishing with a diamond paste (MetaDi, Buehler, $1 \mu \mathrm{m}$ ). The electrolyte solutions were prepared with water purified in a Millipore system $(18.2 \mathrm{M} \Omega \mathrm{cm})$ and analytical-grade reagents (POCh, Poland). The electrolyte solutions were deoxygenated with $\mathrm{N}_{2}$ (5N, Air Products); during the measurements, the $\mathrm{N}_{2}$ stream was directed above the electrolyte level. All the experiments were carried out at room temperature.

A CHI660D potentiostat (CH Instruments) was used in the experiments. Both single-frequency and multiple-frequency impedance measurements were carried out. In the single- 
frequency measurements, a high-frequency $(1465 \mathrm{~Hz}, 5-\mathrm{mV}$ amplitude) AC signal was superimposed on a DC potential scan with 20 - or 50-mV steps. In the constant potential impedance spectroscopy (electrochemical impedance spectroscopy (EIS)), the frequency range of $10.01 \mathrm{kHz}-46.4 \mathrm{mHz}$ with 5 $\mathrm{mV}$ amplitude was usually applied. The EIS spectra were fitted using the Equivert software [52] while for Kramers-Kronig tests, the FRA (EcoChemie) software that allows introduction of greater number of circuit components was used.

A 150-W Xe lamp with a ZXE power supply unit (both Optel, Poland) were used for photocurrent measurements. XPS measurements were carried out in the Institute of Physical Chemistry of Polish Academy of Sciences, Warsaw, with an ESCALAB-210 (VG Scientific) apparatus using an Al X-ray gun, and an Ar ion gun was used for depth profiling. The rate of sputtering with Ar ions varied from 0.31 to $12.7 \mathrm{~nm} \mathrm{~min}^{-1}$ (ion energy from $250 \mathrm{eV}$ to $2 \mathrm{keV}$ ) at various stages of the sputtering process and was calculated in respect to $\mathrm{SiO}_{2} / \mathrm{Si}$ standards (Reference Material No. 564 from the Institute for Reference Materials and Measurements, European Commission-Joint Research Centre). The XPS spectra were fitted using the XPSPeak software [53].

The real surface area of the polycrystalline Ag electrodes was calculated on the basis of the double-layer capacitance determined from EIS measurements at potentials of hydrogen evolution region (HER) $(-1100$ to $-1300 \mathrm{mV})$, where the electrode surface is oxide-free. At higher potentials, the $C_{\mathrm{dlm}}$ measurements may be complicated by adsorption of anions $[15,35$, $54,55]$ or pre-monolayer surface oxidation, suggested in [56]. Further on, the $C_{\mathrm{dlm}}$ varies with the electrode potential between the onsets of the surface oxidation and HER $[19,57]$. The $C_{\mathrm{dlm}}$ measured in HER region was also used as a reference value for comparison with the capacitance of the oxide-covered surfaces.

The EIS spectra were recorded for freshly prepared electrodes not subjected to a previous oxidation and after 90-120 s of polarisation at potentials of HER. The spectra (not shown) were fitted with an equivalent circuit shown in Fig. S1 in Supplementary Material. The circuit contains a parasitic capacitance, $C_{\mathrm{p}}$ (nF range), connected in parallel with a branch which contains a series combination of an ohmic resistance $\left(R_{\mathrm{ohm}}\right)$ and a subcircuit describing the electrolyte-electrolyte interface. The latter subcircuit is composed with two components connected in parallel: a charge transfer resistance $\left(R_{\mathrm{ct}}\right)$ and a constant phase element (CPE), which represents the double-layer capacitance. The CPE impedance is defined as follows [58-60] (3):

$Z_{\mathrm{CPE}}=Q^{-1}(\mathrm{i} \omega)^{-\alpha}$

where $i$ is the imaginary unit, $Q$ is the CPE coefficient, and $\alpha$ is the exponential factor ( $\alpha=1$ for pure capacitance). There is a long discussion in the literature about origins of CPE-type behaviour of the double layer and whether the $Q$ value can be identified as a pure capacitance. In general, the lower is the $\alpha$ value, the higher is the departure from the ideal capacitive behaviour. The reasons of such behaviour include surface roughness, surface non-homogeneity, contribution of various basal planes, adsorption processes, etc. [58-61]. It has been also recommended that $Q$ cannot be considered equal to the pure capacitance unless $\alpha$ is equal to unity $[58,62]$. The $Z_{\mathrm{CPE}}$ can be recalculated into the capacitance units according to [59, 61] (4):

$C_{\mathrm{dlm}}=\left(Q\left(\frac{1}{R_{\mathrm{ohm}}}+\frac{1}{R_{\mathrm{ct}}}\right)^{(\alpha-1)}\right)^{\left(\frac{1}{\alpha}\right)}$

There was no need to include a pseudocapacitance due to hydrogen adsorption, presumably due to a potential independent surface coverage with adsorbed hydrogen at such high overpotentials [63]. It was found that the double-layer capacitance reaches the lowest values and was practically potential independent in -1100 to $-1300-\mathrm{mV}$ range with $\alpha$ and $Q$ value ranges of $0.944-0.961$ and $(2.80-3.25) \cdot 10^{-5} \mathrm{~F} \mathrm{~s}^{\alpha-1}$ for $\mathrm{cm}^{-2}$ of the real surface area, respectively. The surface roughness factor of the freshly prepared electrodes was in the range of $3.3 \pm 0.3$ and was calculated with assumed specific doublelayer capacitance of $20 \mu \mathrm{F} \mathrm{cm}{ }^{-2}$, which is the lowest capacitance value in HER region measured for Ag single crystal electrodes in neutral and acidic electrolytes [64-66]. It is assumed that the real surface area is determined most accurately for single crystals, and for these electrodes, the most reliable values of the specific double-layer capacitance are expected. The higher values of specific $C_{\mathrm{dl}}$ in HER region are also reported for Ag electrodes (e.g. $25-30 \mu \mathrm{F} \mathrm{cm}{ }^{-2}$ range in HER region $[16,17])$, but it should be stressed that selection of the value of the specific double-layer capacitance used for the real surface area determination has no influence on the comparison of $C_{\mathrm{dlm}}$ and $C_{\mathrm{dlox}}$ values discussed later in the text. Therefore, presented conclusions about relation between $C_{\mathrm{dlm}}$ and $C_{\mathrm{dlox}}$ values are valid regardless of the selected specific $C_{\mathrm{dl}}$ value.

Ag oxidation and dissolution may lead to the surface roughening, as already pointed out in [8, 21, 22, 29, 30, 67]. Comparative measurements carried out after completing the Ag oxidation experiments described later in the text showed an increase in $C_{\mathrm{d} l \mathrm{~m}}$ in HER region by $2.0 \pm 0.5$ times $\left(\alpha=0.919-0.942\right.$ and $Q=(7.34-6.17) \cdot 10^{-5} \mathrm{~F} \mathrm{~s}^{\alpha-1} \mathrm{~cm}^{-2}$ in respect to the real surface area determined before the oxidation or $(2.90-3.45) \cdot 10^{-5} \mathrm{~F} \mathrm{~s}^{\alpha-1} \mathrm{~cm}^{-2}$ in respect to the real surface calculated after the oxidation experiments) pointing out to an increase in the electrode real surface area. This conclusion is valid when the previously formed $\mathrm{Ag}_{2} \mathrm{O}$ is completely reduced such that the electrode is oxide free at potentials of HER $[22,74]$. A decrease in $\alpha$ with the surface area increase suggests that the surface roughness is the main factor responsible for lowering the $\alpha$ values. It is important to note that an 
increase in the surface roughness detected at potentials more negative than Ag oxidation, e.g. in HER region, might be caused not only by the electrode dissolution during anodic Ag oxidation. Other processes which may contribute to changes in the surface roughness include surface rearrangement during reduction of $\mathrm{Ag}_{2} \mathrm{O}$ [8, 68, 69] and possible redeposition of dissolved Ag species. Data reported in this manuscript are expressed in respect to the real surface area determined for the electrode not subjected to the anodic oxidation, unless stated otherwise. It should be bearing in mind, however, that a dissolution-induced increase in the surface roughness is expected during the anodic $\mathrm{Ag}$ oxidation.

\section{Results and discussion}

\section{General electrochemical characterisation and XPS results}

Figure 1 shows a cyclic voltammetry $(\mathrm{CV})$ curve recorded for a polycrystalline Ag electrode in $0.1 \mathrm{M} \mathrm{KOH}$ in potential range $486-914 \mathrm{mV}$. The curve reveals complex oxidation currents (A) composed with several overlapped anodic peaks with the onset at ca. $10 \mathrm{mV}$ and a corresponding reduction peak (C) seen at potentials more negative than $100 \mathrm{mV}$ (the exact location depends on the amount of $\mathrm{Ag}$ compounds subjected to the reduction $[37,69])$. Detailed discussion of the processes related to the anodic currents (A) can be found elsewhere [21-29, 70-75]. Various products of Ag oxidation at potentials up to ca. $540 \mathrm{mV}$ are reported in the literature, including soluble $\mathrm{Ag}$ ions, surface $\mathrm{AgOH}$ species and solid $\mathrm{Ag}_{2} \mathrm{O}$ film. Formation of a solid oxide layer at the electrode surface at potentials of peaks (A) was confirmed by e.g. electrochemical quartz crystal microbalance [22, 23], XPS [15] and ellipsometric [76-78] measurements.

The silver oxidation in an alkaline environment can be accompanied by a dissolution of the electrode $[22,23,38$, 67, 72, 77-79], and $\mathrm{Ag}_{2} \mathrm{O}$ itself may undergo a dissolution as well $[22,79]$. Thus, apart from the reduction of the solid

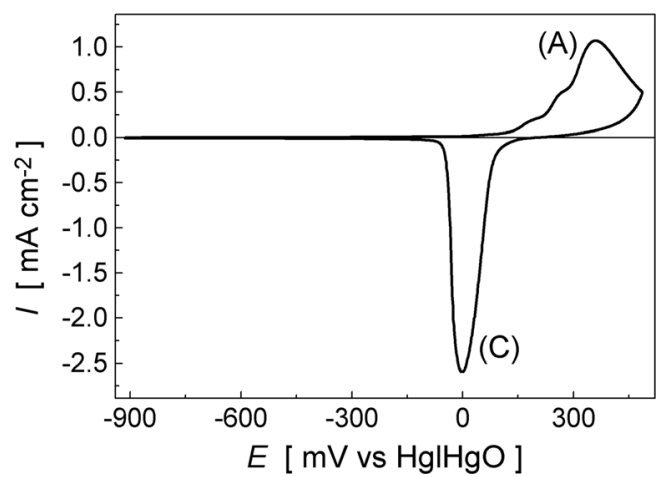

Fig. 1 Cyclic voltammetry curve of an Ag electrode in $0.1 \mathrm{M} \mathrm{KOH}$ with $100 \mathrm{mV} \mathrm{s}^{-1}$. The letters denote current peaks described in the text oxide [22], the charge of peak (C) may also contain a contribution from reduction of soluble $\mathrm{Ag}$ species formed during the electrode oxidation [24, 70-72, 77]. Therefore, the oxide thickness calculated directly on the basis of the oxidation or reduction charge without correction for $\mathrm{Ag}$ dissolution should be treated as an upper limit of the oxide thickness, which may be formed under applied experimental conditions rather than the exact thickness value. It should be pointed out that although quantification of the exact thickness of the oxide layer can be difficult, an analysis of the influence of the oxidation or reduction charge on the impedance data still delivers qualitative information on the electrochemical properties of the system studied. Regarding the potential range investigated in these studies, the experiments with a rotating ring-disk electrode reported in [79] show that for solid Ag electrodes in $0.1 \mathrm{M} \mathrm{KOH}_{\mathrm{aq}}$ and $q_{\mathrm{ox}}$ as high as ca. $1 \mathrm{mC} \mathrm{cm}^{-2}$, the dissolution contributes to the overall oxidation current by no more than $3 \%$ at $355-365 \mathrm{mV}$ vs. $\mathrm{Hg} \mid \mathrm{HgO}$. For $q_{\text {ox }}$ lower than $1 \mathrm{mC} \mathrm{cm}{ }^{-2}$, this contribution was not quantified, but it is expected that at early stages of the oxidation process, when the surface is not completely passivated or the oxide layer is very thin, the dissolution plays a more important role [44].

Figure 2 shows examples of XPS spectra for Ag subjected to oxidation in $0.1 \mathrm{M} \mathrm{KOH}$ at $420 \mathrm{mV}$ and recorded at various stages of the $\mathrm{Ar}^{+}$sputtering. The $\mathrm{Ag}(0) 3 \mathrm{~d} 5 / 2$ peak was fitted with an asymmetric Gaussian-Lorentzian function [39] with a tail extension of 90 and a asymmetry factor of $0.1[53,80]$. The spectra recorded for the fully oxidised surface before the sputtering reveal $\mathrm{Ag} 3 \mathrm{~d} 5 / 2$ and $3 \mathrm{~d} 3 / 2$ peaks at $367.8 \pm 0.1$ and $373.8 \pm 0.1 \mathrm{eV}$, respectively (Fig. 2a). These binding energy (BE) values point out to $\mathrm{Ag}(\mathrm{I})$ in $\mathrm{Ag}_{2} \mathrm{O}$ [11, 81-85]. For $\mathrm{Ag}(\mathrm{I})$, both $3 \mathrm{~d} 5 / 2$ and $3 \mathrm{~d} 3 / 2$ peaks are located at lower $B E$ values as compared to the fully metallic surface, in agreement with [84, 86, 87]. The location of $\mathrm{Ag} \mathrm{M}_{4} \mathrm{VV}$ Auger peak (Fig. 2b) at kinetic energies $(K E)$ of $356.3 \mathrm{eV}$ also confirms the presence of $\mathrm{Ag}_{2} \mathrm{O}$ [81, 87]. Removal of the $\mathrm{Ag}(\mathrm{I})$ layer during $\mathrm{Ar}^{+}$ sputtering (Fig. 2b-d) is indicated by a gradual decrease of $\mathrm{Ag}(\mathrm{I})$ signal accompanied by a growth of $\mathrm{Ag}(0)$ peaks: a $3 \mathrm{~d} 5 /$ 2 peak at $368.2 \pm 0.1 \mathrm{eV}$ and a $3 \mathrm{~d} 3 / 2$ peak at $374.2 \pm 0.1 \mathrm{eV}$. Both $\operatorname{Ag}(0)$ peaks are accompanied by poorly developed satellites at ca. 372.0 and $378.1 \mathrm{eV}$, respectively [88]. It should be noted that a reduction of $\mathrm{Ag}_{2} \mathrm{O}$ during $\mathrm{Ar}^{+}$bombardment [89] may also contribute to the development of the $\operatorname{Ag}(0)$ signal. Addition of $\mathrm{Ag}(\mathrm{III}) 3 \mathrm{~d} 5 / 2$ peak, usually reported at ca. $367.4 \mathrm{eV}[39,81,84]$, has no influence on the fit quality indicating absence of detectable amounts of $\mathrm{AgO}$.

The O1s signal recorded for the oxide-covered sample before the sputtering can be deconvoluted into two components (Fig. 3a-d). The main peak at $528.9 \pm 0.4 \mathrm{eV}$ is attributed to $\mathrm{O}^{2-}$ in a solid oxide phase $[11,87,90]$, and its binding energy is very close to the value reported for oxygen in $\mathrm{Ag}_{2} \mathrm{O}$ in [84]. Interpretation of the second O1s peak at $530.9 \pm 0.4 \mathrm{eV}$, which is observed for the first as well as the subsequent sputtering 
Fig. 2 Ag3d XPS and Auger spectra for the electrode oxidised in $0.1 \mathrm{M} \mathrm{KOH}$ at $420 \mathrm{mV}$ for various stages of the $\mathrm{Ar}^{+}$ sputtering: a $3 \mathrm{~d} 5 / 2$ and $3 \mathrm{~d} 3 / 2$ XPS signals before and after completing (metallic surface) the sputtering, b Auger $\mathrm{M}_{4} \mathrm{VV}$ signals before the sputtering and c-e deconvoluted $3 \mathrm{~d} 5 / 2$ XPS signals recorded before sputtering and after 5 and 16 sputtering cycles, respectively. The sputtering rates were $0.31 \mathrm{~nm} \mathrm{~min}^{-1}$ (cycles 1-20) and $1.52 \mathrm{~nm} \mathrm{~min}^{-1}$ (from 21st cycle), 1 cycle $=2$ min of sputtering. Red lines: experimental data, black lines: fit
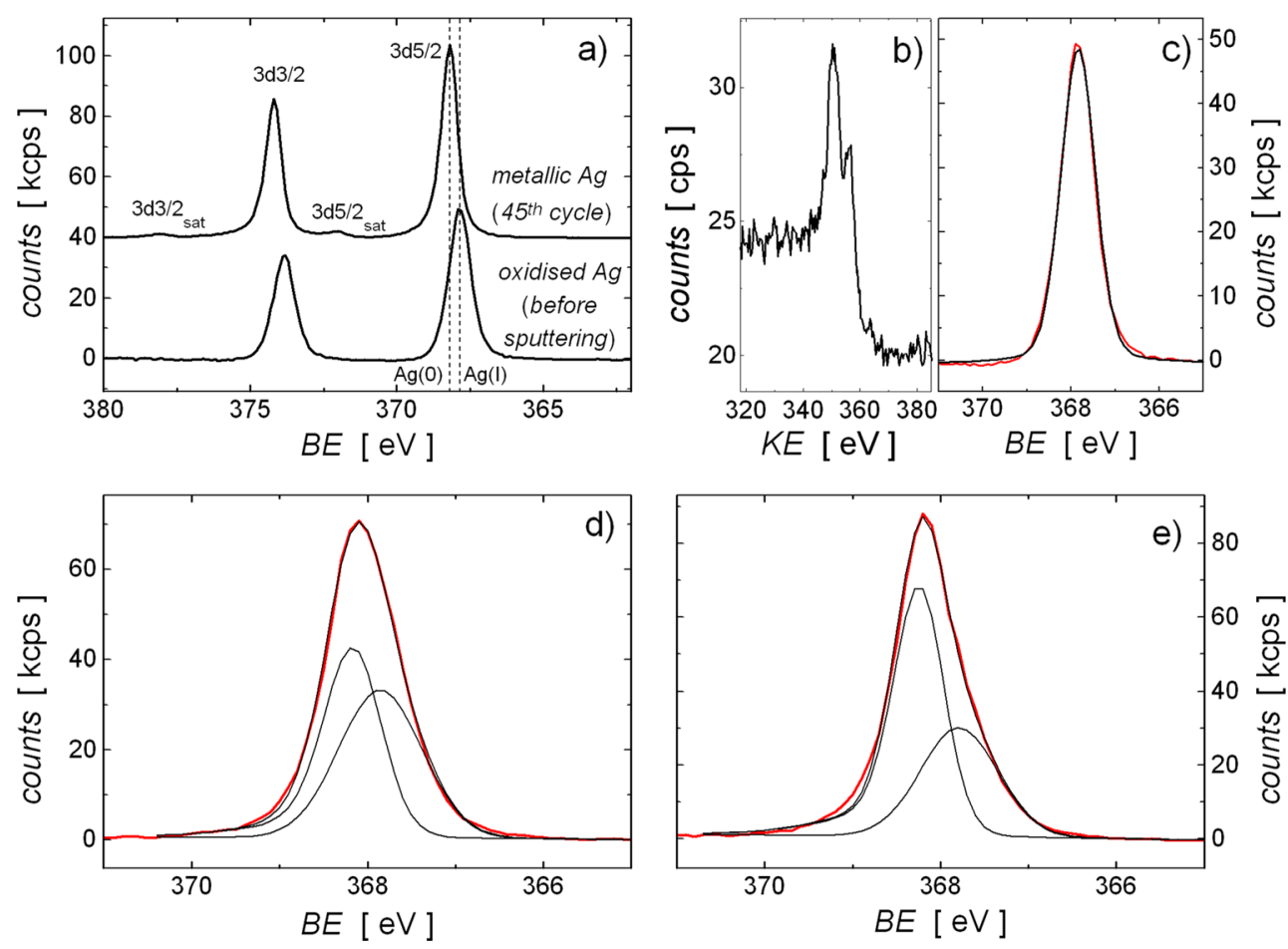

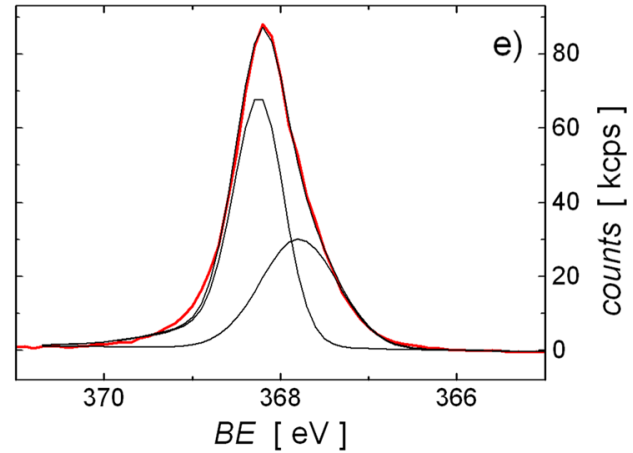

cycles, is more complicated. In the case of spectrum recorded before the sputtering (Fig. 3a), this signal can be linked with surface-adsorbed species: oxygen [11, 87], water or $\mathrm{OH}[91$, 92] or other contaminations. In the case of advanced stages of the sputtering process (Fig. 3b-d) several identifications of this signal may be proposed: it may be attributed to $\mathrm{OH}^{-}$ incorporated into the oxide (XPS experiments presented in [15] indicate possibility of incorporation of the double-layer species into the $\mathrm{Ag}_{2} \mathrm{O}$ film) or other forms of the oxygen dissolved in the bulk of the oxide [86]. It should be noted that $\mathrm{Ag}(\mathrm{I})$ hydroxide is unstable at room temperature and decomposes to $\mathrm{Ag}_{2} \mathrm{O}$ and water [27, 93]. Although formation of
Fig. 3 O1s XPS spectra for the same electrode as in Fig. 2 for various stages of the sputtering process: a before the sputtering and $\mathbf{b}-\mathbf{d}$ recorded after 5,16 and 42 sputtering cycles, respectively. Red lines: experimental data, black lines: fit. e $\mathrm{Ag}(\mathrm{I}) 3 \mathrm{~d} 5 / 2$ to O1s $(528.9 \mathrm{eV})$ XPS peak area ratio as a function of the $\mathrm{Ar}^{+}$ sputtering cycle. The sputtering conditions were the same as for Fig. 2
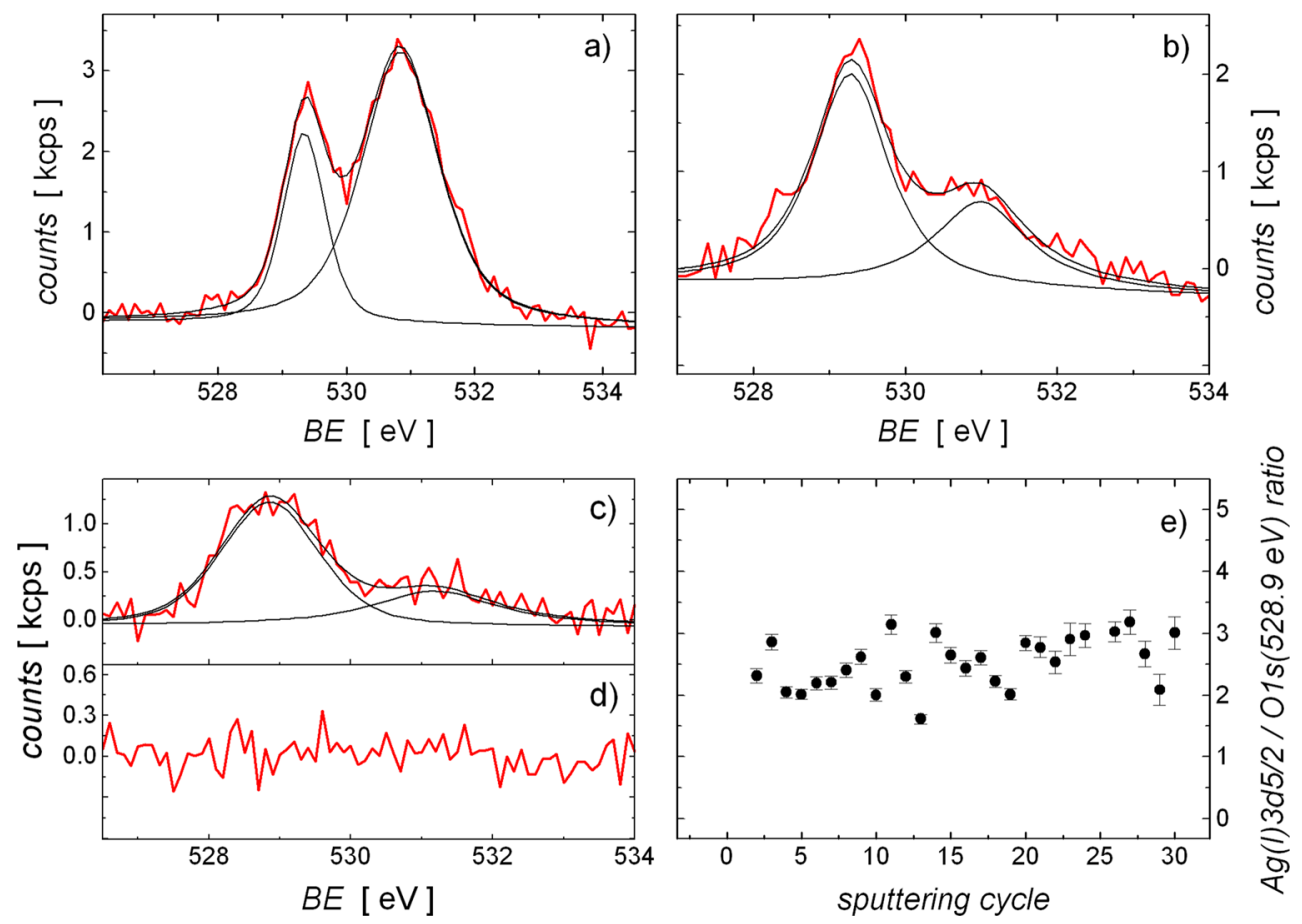
AgOH during anodic Ag oxidation was proposed in [41, 42, 71, 79, 94-97], the existence of silver-hydroxyl ion species under UHV conditions seems to be highly unlikely.

Assuming that $\mathrm{O} 1 \mathrm{~s}$ peak at $528.9 \mathrm{eV}$ is the only structural constituent of the $\mathrm{Ag}_{2} \mathrm{O}$ lattice and other O1s signals are related to incorporated interstitial species, one may evaluate stoichiometry of the film by means of an analysis of the areas of the respective XPS peaks (Fig. 3e). The ratio between areas of $\mathrm{Ag}(\mathrm{I}) 3 \mathrm{~d} 5 / 2$ and $\mathrm{O} 1 \mathrm{~s}(528.9 \mathrm{eV})$ peaks, measured for the surface subjected to the ion etching and corrected for the respective sensitivity factors [98], is greater than 2 and is practically independent on the number of sputtering cycles, indicating that the oxide composition can be considered unchanged across the oxide thickness. It follows then that the electrochemically generated $\mathrm{Ag}_{2} \mathrm{O}$ is oxygen deficient, the effect confirmed by an analysis of semiconducting properties of the film discussed later in the text. Such oxygen deficiency of $\mathrm{Ag}_{2} \mathrm{O}$ film is in line with data reported in [11] for the $\mathrm{Ag}(\mathrm{I})$ oxide formed in more concentrated alkali solution (1 $\mathrm{M} \mathrm{KOH})$ at more positive potential of ca. $535 \mathrm{mV}$. Therefore, the $\mathrm{O} 1 \mathrm{~s}$ signal at $530.9 \mathrm{eV}$ is most likely linked with oxygen species incorporated in the interstitial sites which do not form bond with Ag. These species may neutralise charge of oxygendeficient $\mathrm{Ag}_{2} \mathrm{O}$, and their presence may alter lattice parameters of $\operatorname{Ag}_{2} \mathrm{O}$, as discussed in [77] for hydrous oxides. When the sum of both O1s peaks is considered, the ratio between areas of $\operatorname{Ag}(\mathrm{I}) 3 \mathrm{~d} 5 / 2$ peak and the total oxygen signal varies between 1.3 and 2 for the sample subjected to the ion sputtering.

The charge consumed for the oxide formation or reduction can be recalculated into the number of the oxide layers providing that the oxidation charge passed during formation of a single monolayer of $\mathrm{Ag}_{2} \mathrm{O}$ (single plane containing $\mathrm{Ag}$ and $\mathrm{O}$ ions), $q_{\mathrm{ox}(\mathrm{ml})}$, is known. The number of the monolayers can be further recalculated into the thickness units, required for Eq. (2), when the thickness of a single atomic or molecular layer of the oxide is known. Two approaches of determination of $q_{\mathrm{ox}(\mathrm{ml})}$ are reported in the literature. The first one assumes that the first monolayer of the oxide is described as a chessboardlike structure containing atomic layers with alternatively mixed metal cations and oxygen anions with the overall crystallographic structure and $q_{\mathrm{ox}(\mathrm{ml})}$ the same as for the metal subjected to the oxidation [99]. Alternatively, it may be assumed that the anodically formed oxide has the same structure, lattice constant and $q_{\text {ox(ml) }}$ as the respective bulk oxide obtained by e.g. chemical synthesis [e.g. 7]. It is likely that the crystallographic structure, and consequently $q_{\mathrm{ox}(\mathrm{ml})}$, changes with the oxide thickness due to a possible transition between two abovementioned scenarios of the oxide formation. Therefore, for relatively thin oxide films, such as these studied in this work, it is helpful to find an average value of $q_{\mathrm{ox}(\mathrm{ml})}$, which can be considered representative for the whole oxidised layer. Based on the respective lattice parameters of $\mathrm{Ag}$ ( $\mathrm{fcc}$ structure with the lattice constant of $4.09 \AA[100])$ and $\mathrm{Ag}_{2} \mathrm{O}$ (fcc sublattice of Ag ions with lattice constant of $4.74 \AA$ in cubic cuprite-type structure of $\mathrm{Ag}_{2} \mathrm{O}$ [101-103]), one obtains $q_{\mathrm{ox}(\mathrm{ml})}$ values equal to 192 and $143 \mu \mathrm{C} \mathrm{cm}^{-2}$ for complete one electron oxidation of a single layer of surface atoms of $\mathrm{Ag}$ metal [99] and for formation of a single molecular layer of bulk $\mathrm{Ag}_{2} \mathrm{O}$, respectively (for formation of a complete monolayer of closed packed $\mathrm{AgOH}$, the value of $400 \mu \mathrm{C} \mathrm{cm}^{-2}$ was assumed in $[94,104])$. The average $q_{\mathrm{ox}(\mathrm{ml})}$ is then equal to $168 \mu \mathrm{C} \mathrm{cm}^{-2}$, and this gives the maximum thickness of the oxidised layers studied in this work equal to ca. 106 monolayers (when the surface roughness changes are disregarded and without corrections for $\mathrm{Ag}$ dissolution).

\section{Single-frequency impedance measurements}

The single-frequency impedance measurements with $1465 \mathrm{~Hz}$ were carried out for the oxide-covered Ag electrodes at $365 \mathrm{mV}$. For such high-frequency value, the contribution from the parallel parasitic capacitance described in the "Experimental" section is meaningless, and when the parallel charge transfer resistance is sufficiently high, the condition confirmed by results of EIS spectra analysis shown in Fig. 7 further in the text, the $Z^{\prime \prime}$ can be recalculated into $C_{\text {tot }}$ when a series resistance-capacitance (RC) circuit is assumed. The $C_{\text {tot }}$ measured at a constant potential value decreases with the increase in $q_{\text {ox }}$ (left bottom inset in Fig. 4) in agreement with the relation between and $C_{\mathrm{ox}}$ and $l_{\mathrm{ox}}$ from Eq. 2 and $C_{\mathrm{tot}}$ and $C_{\mathrm{ox}}$ from Eq. 1 and in line with data reported in [9]. Quantitative analysis of this relationship, such as determination of $C_{\mathrm{dlox}}$ or $\varepsilon_{\mathrm{r}}$, is, however, more complicated. Firstly, contribution from Ag dissolution to $q_{\text {ox }}$ must be known: although for $q_{\text {ox }}$ range presented in Fig. 4, this contribution is expected to be practically meaningless and $q_{\text {ox }}$ independent [79], the earlier stages

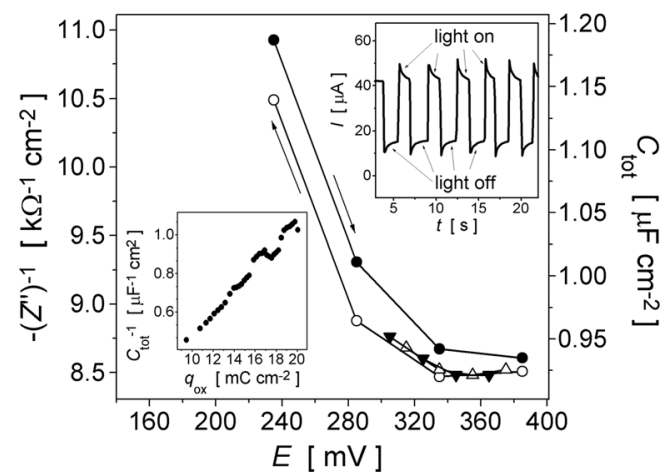

Fig. 4 Main panel: reciprocal of $\left|Z^{\prime \prime}\right|$ (left axis) and corresponding series capacitance $C_{\text {tot }}$ (right axis) for $1465 \mathrm{~Hz}$ as a function of the electrode potential for $\mathrm{Ag}$ oxidised in $0.1 \mathrm{M} \mathrm{KOH}$ at $420 \mathrm{mV}\left(q_{\mathrm{ox}}=20.3 \mathrm{mC} \mathrm{cm}^{-2}\right)$. Shown are the first negative (backward, open points) and subsequent positive (forward, closed points) potential scans. Potential ranges: circles: 235-385 mV, triangles: $375-315$ and 305-365 mV for negative and positive scans, respectively. Left lower inset: $C_{\text {tot }}{ }^{-1}$ measured with $1465 \mathrm{~Hz}$ at $365 \mathrm{mV}$ as a function of $q_{\mathrm{ox}}$. Right upper inset: photocurrents recorded at $420 \mathrm{mV}$ for the oxide-covered $\mathrm{Ag}\left(q_{\text {ox }}=21.5 \mathrm{mC} \mathrm{cm}^{-2}\right)$ 
of the oxidation process might be much stronger affected by the dissolution processes. Secondly, the exact value of the crystallographic cell dimensions must be known: it was reported [77] that the electrochemically formed hydrous oxides may possess ca. 2.5 times greater cell parameters as compared to the anhydrous form [77]. Finally, the contribution of other capacitive elements, such as the surface state capacitance discussed in the next chapter, to the imaginary impedance component, must be also considered.

The main panel in Fig. 4 shows how the $C_{\text {tot }}$ of $\mathrm{Ag}_{2} \mathrm{O}$ covered electrode is influenced by the electrode potential when the impedance is measured at various potential values. Measurements under such conditions are complicated by limited stability of such layers, as discussed in [41]. The oxidised layers, especially the thin ones, may undergo further thickening or partial reduction during the impedance data collection, depending on the applied potential range. The stability of the oxidised layers may be evaluated on the basis of the degree of overlapping of subsequently recorded curves for forward and backward potential scans $[105,106]$. It follows that stability of $\mathrm{Ag}_{2} \mathrm{O}$-covered electrodes depends on the potential range where the impedance was acquired (main panel in Fig. 4). Thus, for a very narrow potential window of ca. 305$375 \mathrm{mV}$, the $Z^{\prime \prime-1}$ (or $C_{\text {tot }}$ ) vs. $E$ curves for negative and positive potential scans practically overlap. An increase of the capacitance with the potential decrease is noted below ca. $345 \mathrm{mV}$, but the very narrow potential range where this effect is observed does not allow drawing definitive conclusions about electronic properties of the $\mathrm{Ag}_{2} \mathrm{O}$ film.

An opposite effect is observed when the negative potential limit is extended to $235 \mathrm{mV}$, which is the value located ca. $30 \mathrm{mV}$ before the apparent potential of the onset of the oxide reduction deduced from the respective voltammetric curves (main panel in Fig. 4). In this case, the capacitance is lower for the subsequent positive potential scan and the curves recorded for both scan directions do not overlap, most likely due to a partial reduction of $\mathrm{Ag}_{2} \mathrm{O}$ : it is likely that deduction of the reduction onset from the voltammetric curves (potential of zero current) gives only a rough estimation of its value. It should be also stressed the Mott-Schottky equation cannot be applied here because the oxide layers are most likely too thin and the measurements were carried out at conditions too close to the full depletion of the semiconductor $\left(C_{\text {tot }}{ }^{-2}\right.$ vs. $E$ plots (not shown) are non-linear) [1, 107]. Therefore, although a decrease of $C_{\text {tot }}$ with increasing potential suggests behaviour of an n-type semiconductor [1, 41-43, 47], the unequivocal proof of such type of properties comes from photocurrent measurements showing formation of positive photocurrents (top right inset in Fig. 4). This type of the photocurrent is observed only for sufficiently thick $\mathrm{Ag}_{2} \mathrm{O}$ layer (at least $10 \mathrm{mC} \mathrm{cm}^{-2}$ ), which confirms its assignment to the semiconducting properties of the film. The n-type semiconducting properties are also in agreement with XPS data discussed in the previous chapter and indicating oxygen deficiency of $\mathrm{Ag}_{2} \mathrm{O}$ [108]. The transient shape of the photocurrents points out to existence of surface states [109]. Such a confirmation of the semiconductor type is important because semiconducting properties of electrochemically formed $\mathrm{Ag}_{2} \mathrm{O}$ may vary depending on formation conditions [21].

\section{Electrochemical impedance spectroscopy}

A two-step potential program was applied in EIS measurements for $\mathrm{Ag}_{2} \mathrm{O}$-covered electrodes with a relatively fast oxide formation at $E_{\mathrm{ox}}=420 \mathrm{mV}$ and subsequent EIS data collection at $E_{\mathrm{m}}=365$ or $345 \mathrm{mV}$ where the rate of faradaic reactions is significantly smaller. Selection of such type of the procedure was driven by two factors. Firstly, it allows significant reduction of time of the experiment as compared to formation of $\mathrm{Ag}_{2} \mathrm{O}$ layers at $E_{\mathrm{m}}$ as low as $345-365 \mathrm{mV}$. Secondly, it was found that stability of the system during the spectra acquisition at $E_{\text {ox }}$ as high as $420 \mathrm{mV}$ was doubtful for the $q_{\text {ox }}$ range studied (details of the stability tests are presented in the next paragraphs). This procedure did not include reduction of the $\mathrm{Ag}_{2} \mathrm{O}$ layer; i.e. after completing the spectra acquisition at $E_{\mathrm{m}}$, the potential was stepped back to $E_{\mathrm{ox}}$ without the oxide reduction and the procedure of the oxide formation at $E_{\mathrm{ox}}$ followed by the impedance measurements at $E_{\mathrm{m}}$ was repeated. The conditions of continuous oxide growth and its accumulation were maintained, and the $q_{\mathrm{ox}}$ used in data analysis was a sum of the charges passed during all previous steps of the oxide formation. The cumulative oxidation time at $420 \mathrm{mV}$ was up to $400 \mathrm{~s}$.

The validity of EIS data acquired after long-time polarisation was analysed by means of a Kramers-Kronigtype test. The impedance spectra were fitted with a Voigttype circuit composed with a network of connected in series subcircuits, each of them containing a resistance and a capacitance connected in series (RC) [110-112]. Two examples are shown in Fig. 5. Figure 5a shows an example of the residual distribution for the spectrum which passed the test, i.e. for the sufficiently thick oxide layer. The number of RC subcircuits (usually 12) used in this equivalent circuit was smaller than the number of the experimental points resulting in a sinusoidal shape of some sections of the residual trace. However, the lack of continuous and consequent departure of the residual trace from the zero line with the residuals distributed below and above the zero line confirms correctness of the acquired EIS data. This indicates very low rate of observed reactions or attainment of steady-state conditions. If a steady state is attained, the related processes might be interpreted in terms of e.g. point defect model [7].

An opposite example is presented in Fig. 5b where a clear departure from random distribution of the residuals is noticed with most of the residuals located above the zero line and with the average departure from the zero line greater than for Fig. 


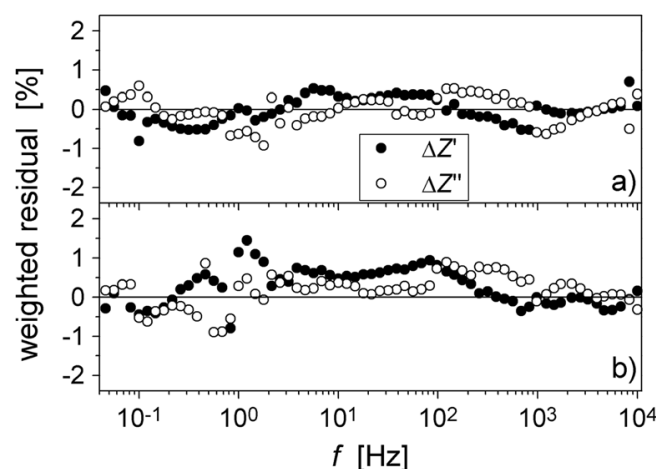

Fig. 5 Examples of distribution of residuals from Kramers-Kronig (KK)type tests for EIS spectra recorded at $365 \mathrm{mV}$ for Ag oxidised at $420 \mathrm{mV}$ for $q_{\mathrm{ox}}=14.0$ (a) and $9.5 \mathrm{mC} \mathrm{cm}^{-2}$ (b). Spectra were fitted with a Voigttype equivalent circuit with $12 \mathrm{RC}$ subcircuits. The residuals are defined as $\Delta Z^{\prime}=100 \cdot\left(Z^{\prime}(\right.$ experiment $\left.)-Z^{\prime}(\mathrm{KK})\right) / \mid Z($ experiment $) \mid$ and $\Delta Z^{\prime \prime}=100 \cdot\left(Z^{\prime \prime}(\right.$ experiment $\left.)-Z^{\prime \prime}(\mathrm{KK})\right) / \mid Z($ experiment $) \mid$

5a. This EIS spectrum was recorded at the early stages of the oxidation procedure when the $\mathrm{Ag}_{2} \mathrm{O}$ layer was relatively thin, and it follows from Fig. $5 \mathrm{~b}$ that its stability was doubtful. In general, the stability required for EIS measurements under conditions of potentiostatic polarisation is observed for $q_{\mathrm{ox}}$ of at least $14 \mathrm{mC} \mathrm{cm}^{-2}$, for a potential window located between ca. 345 and ca. $365 \mathrm{mV}$ and long enough polarisation at $E_{\mathrm{m}}$, usually from 240 to $180 \mathrm{~s}$. It should be noted that for sufficiently long polarisation times, the subsequently recorded spectra reveal very small differences indicating very low rate of faradaic processes at $E_{\mathrm{m}}$. The abovementioned potential window of the system stability under conditions of EIS measurements is significantly narrower than the one for the singlefrequency impedance measurements from Fig. 4 indicating more challenging stability conditions for acquisition of EIS spectra with a long-time polarisation.

Examples of EIS data recorded at $365 \mathrm{mV}$ for various $q_{\mathrm{ox}}$ values are shown in Fig. 6a (Nyquist plots) and 6b (Bode plots). In all cases, a semicircle is observed on Nyquist plots (Fig. 6a), indicating that the electrode does not behave as an ideally polarisable one even for the thickest oxide layers studied (up to ca. $20 \mathrm{mC} \mathrm{cm}$ ). Similar shapes of the Nyquist plots with a semicircle distorted to a various degree were shown in $[9,41,47]$ for $\mathrm{Ag}$ oxidised in alkaline electrolytes in a potential range similar to that investigated in this work. Figure 6a indicates that the radius of the apparent semicircle of the Nyquist plots increases when $q_{\text {ox }}$ increases, indicating that the rate of the faradaic reactions decreases when the oxide layer becomes thicker.

Several factors were considered in selection of the best equivalent circuit used for EIS data fitting; the most important one was the fit quality which was evaluated on the basis of $\chi^{2}$ values (usually $1 \cdot 10^{-4}-5 \cdot 10^{-5}$ range), residual distribution and values of the relative errors of the individual circuit components [105]. The number of the circuit components was optimal so that introduction of additional components had
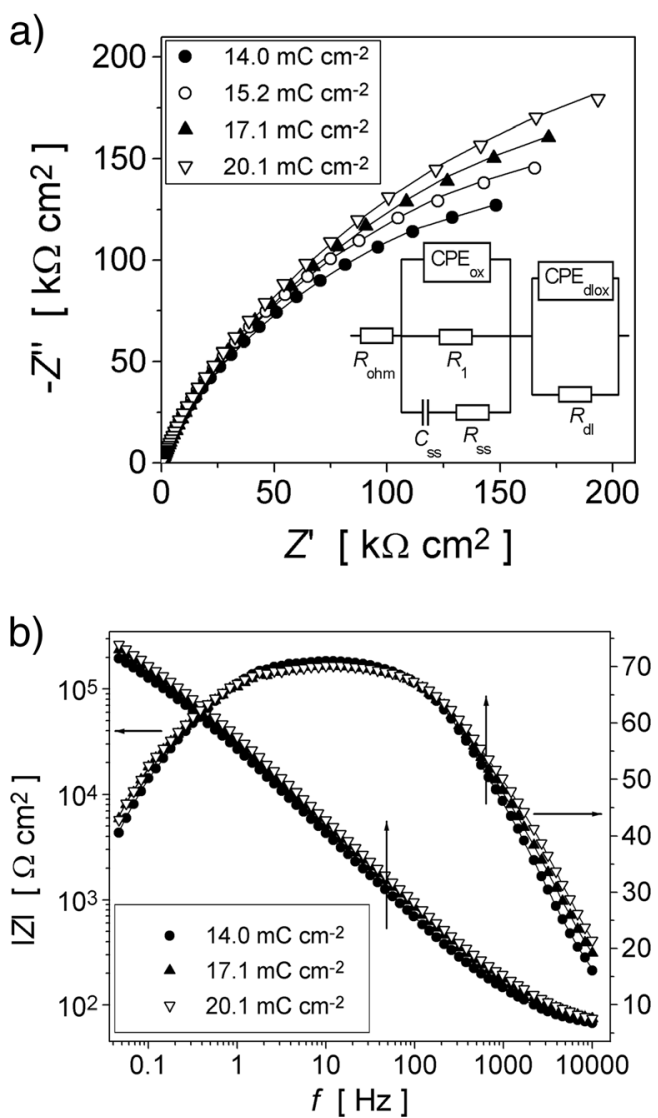

Fig. 6 EIS data recorded in $0.1 \mathrm{M} \mathrm{KOH}$ at $365 \mathrm{mV}$ for an $\mathrm{Ag}$ electrode oxidised at $420 \mathrm{mV}$ for various $q_{\text {ox }}$ values indicated in the plot: a Nyquist and b Bode plots. Points: experimental data, lines: fits to the equivalent circuit shown in the inset in a. The circuit components are explained in the text. Vertical arrows in $\mathbf{b}$ indicate evolution of the plots with increasing $q_{\text {ox }}$; for clarity, $\mathbf{b}$ shows spectra for only three $q_{\text {ox }}$ values

no significant influence on the results of the fitting and only a single set of the fitting parameters gave the best fit.

The equivalent circuit used in the analysis of EIS data is depicted in the inset in Fig. 6a; for the sake of clarity not shown is the parallel parasitic capacitance $\left(C_{\mathrm{p}}\right)$ described in the "Experimental" section and depicted in Fig. S1 in the supplementary material. The two subcircuits of the equivalent circuit from Fig. 6a represent both sides of the electrodeelectrolyte interface between $\mathrm{Ag}_{2} \mathrm{O}$ and $0.1 \mathrm{M} \mathrm{KOH}_{\mathrm{aq}}$. It is assumed that the oxide layers studied are so thick that the electrolyte cannot penetrate them to the metallic surface and the latter effect is disregarded. On the electrolyte side of the interface, the double-layer capacitance is represented as CPE $\left(\mathrm{CPE}_{\mathrm{dlox}}\right)$ with $R_{\mathrm{dl}}$ as the parallel charge transfer resistance describing the rate of a red-ox reaction at the electrode/ electrolyte interface with an electron transfer through it (e.g. [7]). The oxide side contains the capacitance of the $\mathrm{Ag}_{2} \mathrm{O}$ film, represented as another one $\mathrm{CPE}\left(\mathrm{CPE}_{\mathrm{ox}}\right)$, and two parallel branches: the one containing the resistance $R_{1}$ related to faradaic processes of Ag oxidation and another one branch, which describes surface states with the respective capacitance $\left(C_{\mathrm{ss}}\right)$ 
and the resistance $\left(R_{\mathrm{ss}}\right)$. Existence of the surface states is indicated by the shape of the photocurrents recorded for the oxidised Ag electrode (Fig. 4), and addition of $C_{\mathrm{ss}}$ and $R_{\mathrm{ss}}$ to the equivalent circuit significantly improves quality of the fit $\left(\chi^{2}\right.$ decreases by a factor of up to 8 ). Two main differences between the circuit from Fig. 6a and the one used in [9] are the lack of another one $\mathrm{RC}$ branch parallel to $\mathrm{CPE}_{\mathrm{ox}}$, which introduction did not affect quality of the fitting, and the presence of the additional subcircuit $\left(\mathrm{CPE}_{\mathrm{dlox}}-R_{\mathrm{dl}}\right)$ that represents the doublelayer side of the electrode/electrolyte interface. The spectra also do not reveal the Warburg element reported in [10, 47]; its introduction to the equivalent circuit does not improve the fit significantly and leads to unacceptable errors of some of the fitting parameters (up to hundreds of \%). On the other hand, replacement of $C_{\mathrm{ss}}$ with the Warburg impedance deteriorates quality of the fit. Presumably, the layers studied in this work are thinner than those analysed in $[10,47]$ and this may explain discussed differences. The differences between the circuit from Fig. 6a and the one used in [41, 47] include the presence of an additional branch describing surface states $\left(R_{\mathrm{ss}}\right.$ and $\left.C_{\mathrm{ss}}\right)$ and replacement of the capacitances with CPEs. Further on, the frequency range used in this work was extended towards lower values as compared [41, 47].

The respective fits to the circuit from the inset in Fig. $6 \mathrm{a}$ are shown as solid lines in Fig. 6a, b. The values of the fitted components obtained for $E_{\mathrm{m}}=365 \mathrm{mV}$ are shown in Fig. 7 as a function of the oxidation charge without correction for possible Ag dissolution. According to [79], the contribution from the $\mathrm{Ag}$ dissolution current for this $q_{\mathrm{ox}}$ range reaches a few percent and is $q_{\mathrm{ox}}$ independent. Thus, $q_{\mathrm{ox}}$ changes seen in Fig. 7 directly mirror evolution of the $\mathrm{Ag}_{2} \mathrm{O}$ thickness although the exact value of the latter is unclear due to a possible extensive dissolution at the early stages of the oxidation $\left(q_{\mathrm{ox}}<1 \mathrm{mC} \mathrm{cm}^{-2}\right)$ [79]. The $q_{\mathrm{ox}}$ range from Fig. 7 without corrections for the dissolution covers the thickness range ca. 49-105 monolayers when the surface roughening during the oxidation is disregarded or ca. 23-50 monolayers when a surface increase deduced from a comparison of $C_{\mathrm{dl}}$ measured in HER region before and after the oxidation is considered. Not shown is $R_{\mathrm{dl}}$ which is independent on $q_{\mathrm{ox}}$ with the average value of $11.5 \mathrm{k} \Omega \mathrm{cm}^{2}$ and the average error of $22.3 \%$.

An analysis of Fig. 7 indicates that

- $\alpha\left(\mathrm{CPE}_{\mathrm{ox}}\right)$ is the thickness independent, indicating that the physical/chemical properties of the oxide film do not change significantly with its thickness, in agreement with XPS data (Figs. 2 and 3) showing chemical homogeneity of the oxide layer. The relatively low values of $\alpha\left(\mathrm{CPE}_{\mathrm{ox}}\right)$ in the range of $0.781-0.759$ can be attributed to a high defectiveness of the oxide layer. The XPS results (Fig. 3) show non-stoichiometry of the film, and one may expect the presence of local non-homogeneities of the film due to existence of randomly distributed domains with

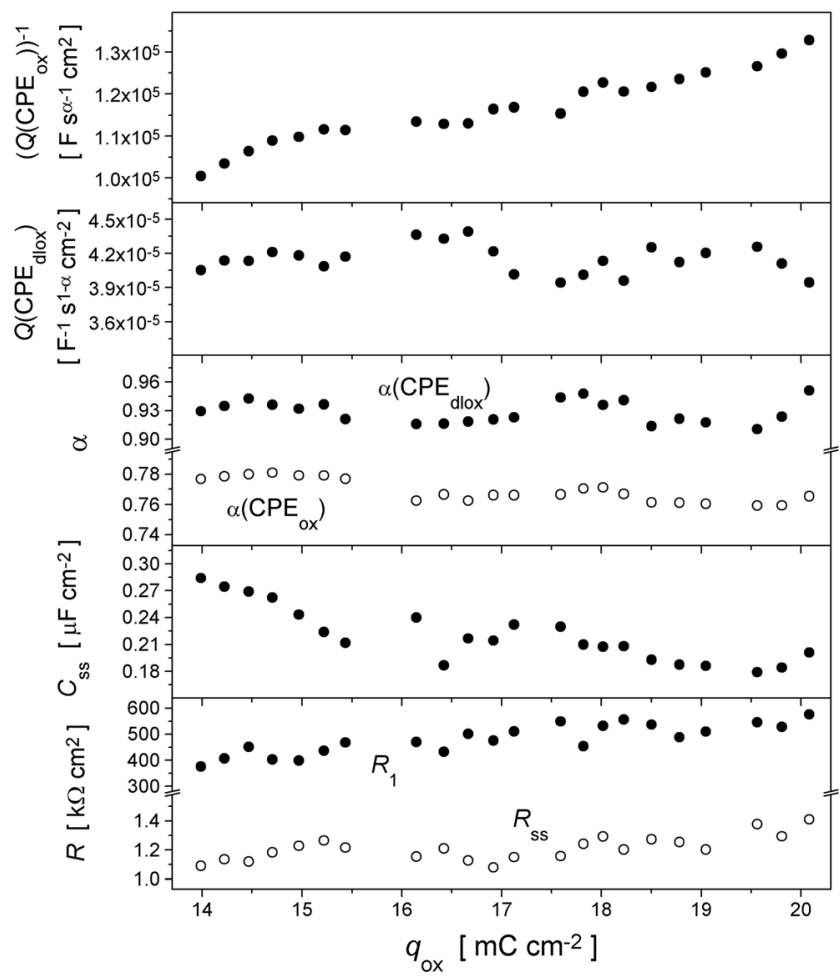

Fig. 7 Components of the equivalent circuit from Fig. 6 as a function of $q_{\text {ox }}$. The average relative errors are (in \%) $4.1\left(Q\left(\mathrm{CPE}_{\mathrm{ox}}\right)\right), 0.5$ $\left(\alpha\left(\mathrm{CPE}_{\mathrm{ox}}\right)\right), 21.1\left(R_{\mathrm{ss}}\right), 16.5\left(C_{\mathrm{ss}}\right), 5.1\left(R_{1}\right), 9.8\left(Q\left(\mathrm{CPE}_{\mathrm{dlox}}\right)\right)$ and 4.2 $\left(\alpha\left(\mathrm{CPE}_{\mathrm{dlox}}\right)\right)$

varying stoichiometries and oxygen content, which may differ also in respect to dielectric/electronic properties. These non-homogeneities are most likely randomly distributed along parallel and horizontal axis of the film, and due to their random distribution, their existence does not result in macroscopic homogeneities of the film, such as formation of layered sandwich-type structures possible to detect by XPS. It was proposed $[59,61]$ that the CPE-type behaviour of non-homogenous 3D films can be described as a normal or series combination of numerous $\mathrm{RC}$ subcircuits with different time constant values. Accordingly, the $\alpha$ value may mirror distribution of respective time constants inside the film volume [61, 113]: the lower the $\alpha$ value, the greater the difference between electric/dielectric properties of domains with different stoichiometry and oxygen content and/or the less sharp is their distribution.

- For the thickness-independent $\alpha\left(\mathrm{CPE}_{\mathrm{ox}}\right)$, the $Q\left(\mathrm{CPE}_{\mathrm{ox}}\right)^{-1}$ vs. $q_{\text {ox }}$ plot shown in Fig. 7 can be analysed in terms of the oxide thickness influence on $Q\left(\mathrm{CPE}_{\mathrm{ox}}\right)$ and indicates that the latter parameter decreases from $9.96 \cdot 10^{-6}$ to $7.53 \cdot 10^{-6} \mathrm{~F} \mathrm{~s}^{\alpha-1} \mathrm{~cm}^{-2}$ when the oxide thickness increases. Although the $Q\left(\mathrm{CPE}_{\mathrm{ox}}\right)^{-1}$ vs. $q_{\mathrm{ox}}$ plot can be approximated by a straight line, in apparent agreement with Eq. 2, it should be bearing in mind that for $\alpha$ values 
as low as $0.7-0.8$, the $Q\left(\mathrm{CPE}_{\mathrm{ox}}\right)$ cannot be identified as the pure capacitance.

- $\quad$ As expected for the double layer, the $Q\left(\mathrm{CPE}_{\mathrm{dlox}}\right)((3.94$ $4.39) \cdot 10^{-5} \mathrm{~F} \mathrm{~s}^{\alpha-1} \mathrm{~cm}^{-2}$ range $), \alpha\left(\mathrm{CPE}_{\mathrm{dlox}}\right)(0.910-0.951$ range) and $R_{\mathrm{dl}}$ (not shown, $10.7-12.3 \mathrm{k} \Omega \mathrm{cm}^{2}$ range) are thickness independent. Relatively low values of $\alpha\left(\mathrm{CPE}_{\mathrm{dlox}}\right)$ are attributed to the rough surface of $\mathrm{Ag}_{2} \mathrm{O}$ $[8,22,29,30,67,77]$; their independence on the oxide thickness may indicate that for the sufficiently thick oxide, the surface roughness becomes practically constant. It is likely that the surface roughening takes place mainly at the initial stages of the oxide formation, when significant sections of the metallic Ag surface are exposed to the electrolyte or the oxide is very thin. For sufficiently thick $\mathrm{Ag}_{2} \mathrm{O}$ layers, the surface becomes more stable and the dissolution, if takes place, does not change the surface roughness significantly although changes in the surface state capacitance are detected (see next point).

- $C_{\mathrm{ss}}\left(0.18-0.28 \mu \mathrm{F} \mathrm{cm}^{-2}\right.$ range) and $R_{\mathrm{ss}}(1.08-$ $1.41 \mathrm{k} \Omega \mathrm{cm}^{2}$ range) decrease and increase with $q_{\mathrm{ox}}$, respectively. This effect indicates some evolution of the oxide-electrolyte interface although without significant changes in the surface roughness, as discussed earlier. The values of both elements are within typically reported ranges [e.g. [114, 115].

- $\quad R_{1}\left(376-576 \mathrm{k} \Omega \mathrm{cm}^{2}\right.$ range) increases with the oxide thickness indicating that the related faradaic process becomes slower when the oxide thickness increases. These values of the charge transfer resistance are significantly greater than $10^{1} \Omega \mathrm{cm}^{2}$ range reported for similar potential range in $[10,47]$.

A very narrow potential range where the EIS spectra were acquired complicates drawing unambiguous conclusions about the potential impact on the fitting parameters. A comparison of data from Fig. 7 with results of EIS measurements at $345 \mathrm{mV}$ (results not shown) does not reveal a clear potential influence on any of the fitting parameters.

The CPE impedance components $Q$ and $\alpha$ obtained for the double layer of the oxide-covered electrode $\left(\mathrm{CPE}_{\mathrm{dlox}}\right)$ can be compared with the respective values for the oxidefree silver measured at potentials of HER. In the case of the electrode from Fig. 7, the average $Q$ and $\alpha$ values in the HER region were equal to, respectively, 2.86 . $10^{-5} \mathrm{~F} \mathrm{~s}^{\alpha-1} \mathrm{~cm}^{-2}$ and 0.953 before the surface oxidation experiments and $7.14 \cdot 10^{-5} \Omega \mathrm{s}^{\alpha} \mathrm{cm}^{-2}$ and 0.929 after completing the oxidation experiments when the surface roughness is expected to increase (both $Q$ values measured for HER region and $Q$ for $\mathrm{CPE}_{\mathrm{dlox}}$ are expressed in respect to the real surface area measured before the oxidation experiments). A comparison of the above values with data from Fig. 7 indicates that the double-layer capacitance of the $\mathrm{Ag}_{2} \mathrm{O}$-covered electrode does not differ significantly from that measured for the metallic surface: $\alpha$ is of the same range while $Q\left(\mathrm{CPE}_{\mathrm{dlox}}\right)$ lies between $Q$ values measured in HER region before and after completing the oxidation experiments. Thus, an analysis of EIS data indicates that the difference between double-layer capacitances of $\mathrm{Ag}_{2} \mathrm{O}$-covered and metallic $\mathrm{Ag}$ electrodes is not as high as an order of magnitude or more, as previously reported.

\section{Conclusions}

Oxidation of polycrystalline solid Ag electrodes in $0.1 \mathrm{M}$ $\mathrm{KOH}_{\mathrm{aq}}$ at $420 \mathrm{mV}$ vs. $\mathrm{Hg} \mid \mathrm{HgO}$ leads to formation of a homogenous anodic oxide layer containing $\mathrm{Ag}_{2} \mathrm{O}$ as follows from an XPS analysis. The electrochemical impedance experiments were applied to study the properties of the interface between the electrolyte and the $\operatorname{Ag}(\mathrm{I})$ oxide-covered electrode; the measurements were carried out under conditions of $\mathrm{Ag}_{2} \mathrm{O}$ film stability, i.e. in 305-375-mV range for single-frequency experiments $(1465 \mathrm{~Hz})$ and in 345-365$\mathrm{mV}$ range for the EIS measurements $(46.4 \mathrm{mHz}-$ $10.01 \mathrm{kHz})$. The overall interfacial capacitance of the electrode/electrolyte interface determined from the singlefrequency measurements decreases with the progress in the surface oxidation process and weakly increases with the potential decrease pointing out to n-type semiconducting properties of the $\mathrm{Ag}_{2} \mathrm{O}$ layer, confirmed by means of photocurrent measurements. An analysis of the influence of the charge of the $\mathrm{Ag}_{2} \mathrm{O}$ formation on the impedance spectra allowed identification of components of the equivalent circuit used in EIS data analysis. The value of the coefficient of the constant phase element (CPE) describing the capacitance of the $\mathrm{Ag}_{2} \mathrm{O}$ layer depends on the oxide thickness while the components of the $\mathrm{CPE}$ attributed to the capacitance of the double layer of the oxide-covered electrode $\operatorname{are~} \mathrm{Ag}_{2} \mathrm{O}$ thickness independent. The latter CPE components were found to be comparable to those obtained for the oxide-free surface at potentials of the HER. This indicates that the double-layer capacitances of oxidised and oxide-free Ag electrode in an alkaline electrolyte are comparable.

Acknowledgements This work was financially supported by Ministry of Science and Higher Education grant No. N N204 125037 and by Faculty of Chemistry, University of Warsaw (BST). The author is greatly indebted to Dr. J. Sobczak and Dr. hab. W. Lisowski, Institute of Physical Chemistry, Polish Academy of Sciences, for XPS measurements.

Open Access This article is distributed under the terms of the Creative Commons Attribution 4.0 International License (http:// creativecommons.org/licenses/by/4.0/), which permits unrestricted use, distribution, and reproduction in any medium, provided you give appropriate credit to the original author(s) and the source, provide a link to the Creative Commons license, and indicate if changes were made. 


\section{References}

1. Stimming U (1986) Electrochim Acta 31:415-429

2. Fierro JLG (2005) Metal oxides: chemistry and applications. CRC Press, Boca Raton

3. Gomes WP, Cardon F (1982) Prog Surf Sci 12:155-215

4. Albery WJ, O'Shea GJ, Smith AL (1996) J Chem Soc Faraday Trans 92:4083-4085

5. Bard AJ, Memming R, Miller B (1991) Pure Appl Chem 63:569_ 596

6. Trasatti S, Petrii OA (1991) Pure Appl Chem 63:711-734

7. Sun A, Franc J, MacDonald D (2006) J Electrochem Soc 153: B260-B277

8. Giles RD, Harrison JA, Thirsk HR (1969) J Electroanal Chem 22: 375-388

9. Hepel M, Tomkiewicz M (1985) J Electrochem Soc 132:32-38

10. Pound BG, MacDonald DD (1982) Electrochim Acta 27:14891500

11. Lützenkirchen-Hecht D, Strehblow HH (2009) Surf Interface Anal 41:820-829

12. Łukomska A, Sobkowski J (2005) J Solid State Electrochem 9: 277-283

13. Safonov VA, Choba MA, Seropegin YD (2003) J Electroanal Chem 552:153-162

14. Larkin D, Guyer KL, Hupp JT, Weaver MJ (1982) J Electroanal Chem 138:401-423

15. Lützenkirchen-Hecht D, Strehblow HH (1998) Electrochim Acta 43:2957-2968

16. Safonov VA, Krivenko AG, Choba MA (2008) Electrochim Acta 53:4859-4866

17. Rojhantalab HM, Richmond GL (1989) J Phys Chem 93:32693275

18. Trunov AM (1989) Sov Prog Chem 55:51-53

19. Perkins RS, Tilak BV, Conway BE, Kozlowska HA (1972) Electrochim Acta 17:1447-1469

20. Takehara Z, Namba Y, Yoshizawa S (1968) Electrochim Acta 13: 1395-1403

21. Perkins RS, Tilak BV, Conway BE, Kozlowska HA (1972) Electrochim Acta 17:1471-1489

22. Chen SL, Wu BL, Cha CS (1996) J Electroanal Chem 416:53-59

23. Chen SL, Wu BL, Cha CS (1997) J Electroanal Chem 420:111118

24. El Rehim SA, Hassan HH, Ibrahim MAM, Amin MA (1998) Monatsh Chem 129:1103-1117

25. Łukaszewski M, Klimek K, Czerwiński A (2009) J Electroanal Chem 637:13-20

26. Jović BM, Jović VD (2004) J Serb Chem Soc 69:153-166

27. Vvedenskii A, Grushevskaya S, Kudryashov D, Kuznetsova T (2007) Corr Sci 49:4523-4541

28. Hepel M, Tomkiewicz M (1984) J Electrochem Soc 131:12881294

29. Wan Y, Wang X, Liu S, Li Y, Sun H, Wang Q (2013) Int J Electrochem Sci 8:12837-12850

30. Kunze J, Strehblow HH, Staikov G (2004) Electrochem Commun 6:132-137

31. Hecht D, Frahm R, Strehblow HH (1996) J Phys Chem 100: 10831-10833

32. Mikhlin YL, Vishnyakova EA, Romanchenko AS, Saikova SV, Likhatski MN, Larichev YV, Tuzikov FV, Zaikovskii VI, Zharkov SM (2014) Appl Surf Sci 297:75-83

33. Savinova ER, Zemlyanov D, Pettinger B, Scheybal A, Schlögl R, Doblhofer K (2000) Electrochim Acta 46:175-183

34. Dirkse TP (1990) Electrochim Acta 35:1445-1449

35. Horswell SL, Pinheiro ALN, Savinova ER, Pettinger B, Zei MS, Ertl G (2004) J Phys Chem B 108:18640-18649
36. Briggs GWD, Fleischmann M, Lax DJ, Thirsk HR (1968) Trans Faraday Soc 64:3120-3127

37. Lopez Teijelo M, Vilche JR, Arvía AJ (1982) J Electroanal Chem 131:331-339

38. Droog JMM, Alderliesten PT, Bootsma GA (1979) J Electroanal Chem 99:173-186

39. Ferraria AM, Carapeto AP, Botelho do Rego AM (2012) Vacuum 86:1988-1991

40. Grzelak A, Jaroń T, Mazej Z, Michałowski T, Szarek P, Grochala W (2015) J Electron Spectrosc Relat Phenom 202:38-45

41. Popkirov GS, Burmeister M, Schindler RN (1995) J Electroanal Chem 380:249-254

42. Kudryashov DA, Grushevskaya SN, Vvedenskii AV (2007) Protect Metals 43:591-599

43. Memming R, Möllers F, Neumann G (1970) J Electrochem Soc $117: 451-457$

44. Vvedenskii A, Grushevskaya S, Kudryashov D, Ganzha S (2010) J Solid State Electrochem 14:1401-1413

45. Jiang Z, Huang S, Qian B (1994) Electrochim Acta 39:2465-2470

46. Ross D, Roberts EFI (1976) Electrochim Acta 21:371-375

47. Naoi K, Nagase Y, Osaka T (1985) J Metal Finishing Soc Jap 36: 404-408

48. Popkirov GS, Schindler RN (1992) Rev Sci Instr 63:5366-5372

49. König U, Schultze JW (1999) In: Wieckowski A (ed) Interfacial electrochemistry: theory, experiment, and applications. New York, Dekker

50. De Gryse R, Gomes WP, Cardon F, Vennik (1975) J Electrochem Soc 122:711-712

51. Nozik AJ, Memming R (1996) J Phys Chem 100:13061-13078

52. Boukamp BA (1986) Solid State lonics 20:31-44

53. Software manual (2016) The University of Warwick http://www2. warwick.ac.uk/fac/sci/physics/research/condensedmatt/surface/ exp/xps/links/xpspeak manual.doc. Accessed 5 Apr 2017

54. Iwasaki N, Sasaki Y, Nishina Y (1988) Surf Sci 198:524-540

55. Lucas CA, Thompson P, Gründer Y, Markovic NM (2011) Electrochem Commun 13:1205-1208

56. Nagle LC, Ahern AJ, Burke LD (2002) J Solid State Electrochem 6:451-462

57. Giles RD, Harrison JA (1970) J Electroanal Chem 24:399-407

58. Sluyters-Rehbach M (1994) Pure Appl Chem 66:1831-1891

59. Brug GJ, Van Den Eeden ALG, Sluyters-Rehbach M, Sluyters JH (1984) J Electroanal Chem 176:275-295

60. Lasia A (1999) In: Conway BE (ed) Electrochemical impedance spectroscopy and its applications, vol 32. New York, Kluwer

61. Hirschorn B, Orazem ME, Tribollet B, Vivier V, Frateur I, Musiani M (2010) Electrochim Acta 55:6218-6227

62. Zoltowski P (1998) J Electroanal Chem 443:149-154

63. Jafarian M, Mahjani MG, Azizi O, Gobal F (2003) Ind J Chem 42 : 516-519

64. Smoliński S, Zelenay P, Sobkowski J (1998) J Electroanal Chem 442:41-47

65. Łukomska A, Sobkowski J (2006) Electrochim Acta 51:22472254

66. Hamelin A, Doubova L, Stoicoviciu L, Trasatti S (1988) J Electroanal Chem 244:133-145

67. Maurice V, Klein LH, Strehblow HH, Marcus P (2007) J Phys Chem C 111:16351-16361

68. Gómez Becerra J, Arvia AJ (1990) Electrochim Acta 35:595-604

69. Lopez Teijelo M, Vilche JR, Arvía AJ (1984) J Electroanal Chem 162:207-224

70. Hur TU, Chung WS (2005) J Electrochem Soc 152:A179-A185

71. Alonso C, Salvarezza RC, Vara JM, Arvia AJ (1990) Electrochim Acta 35:489-496

72. Ambrose J, Barradas RG (1974) Electrochim Acta 19:781-786

73. Sasaki H, Toshima S (1975) Electrochim Acta 20:201-207 
74. Cheng Y, Yan M, Jiang Z (2007) Electrochem Solid-State Lett 10: F5-F8

75. Iwasaki N, Sasaki Y, Nishina Y (1988) J Electrochem Soc 135: 2531-2534

76. López Teijelo M, Zerbino JO, Vilche JR, Arvía AJ (1984) Electrochim Acta 29:939-946

77. Zerbino J, Lopez Teijelo M, Vilche JR, Arvia AJ (1985) Electrochim Acta 30:1521-1525

78. Droog JMM (1980) J Electroanal Chem 115:225-233

79. Vvedenskii A, Grushevskaya S, Kudryashov D (2008) Corr Sci 50:583-590

80. Conny JM, Powell CJ (2000) Surf Interface Anal 29:856-872

81. Waterhouse GIN, Bowmaker GA, Metson JB (2001) Appl Surf Sci 183:191-204

82. Feng HL, Gao XY, Zhang ZY, Ma JM (2010) J Korean Phys Soc 56:1176-1179

83. Weaver JF, Hoflund GB (1994) J Phys Chem 98:8519-8524

84. Hoflund GB, Hazos ZF, Salaita GN (2000) Phys Rev B 62:1112611133

85. Gao XY, Ma JM, Chen C, Zhao MK, Gu JH, Lu JX (2012) J Korean Phys Soc 60:807-811

86. Kaspar TC, Droubay T, Chambers SA, Bagus PS (2010) J Phys Chem C 114:21562-21571

87. Schön G (1973) Acta Chem Scandinav 27:2623-2633

88. Leiro J, Minni E, Suoninen E (1983) J Phys F: Met Phys 13:215221

89. Kim KS, Baitinger WE, Amy W, Winograd N (1974) J Electron Spectr Related Phenom 5:351-367

90. Lützenkirchen-Hecht D, Strehblow HH (2006) Surf Interface Anal 38:686-690

91. Kuch W, Schulze M, Schnurnberger W, Bolwin K (1993) Surf Sci 287-288:600-604

92. Yamamoto S, Bluhm H, Andersson K, Ketteler G, Ogasawara H, Salmeron M, Nilsson A (2008) J Phys Condens Matter 20:184025

93. Wei J, Lei Y, Jia H, Cheng J, Hou H, Zheng Z (2014) Dalton Trans 43:11333-11338

94. Gomez Becerra J, Salvarezza RC, Arvia AJ (1988) Electrochim Acta 33:1431-1437
95. Burstein GT, Newman RC (1980) Electrochim Acta 25:10091013

96. Dirkse TP, De Vries DB (1959) J Phys Chem 63:107-110

97. Jovic BM, Jovic VD, Stafford GR (1999) Electrochem Commun $1: 247-251$

98. Wagner CD, Riggs WM, Davis LE, Moulder JF, Muilenberg GE (1979) Handbook of X-ray photoelectron spectroscopy. Physical Electronics, Eden Prairie

99. Conway BE, Barnett B, Angerstein-Kozlowska H, Tilak BV (1990) J Chem Phys 93:8361-8373

100. Haynes WM (2012) CRC handbook of chemistry and physics. CRC Press, Boca Raton

101. Allen JA (1965) In: Friend JA, Gutmann F (eds) Proc First Australian Conf Electrochem. Pergamon, London

102. Werner A, Hochheimer HD (1982) Phys Rev B 25:5929-5934

103. Zarechina ES, Karzhavykh DS, Kravchenko NG, Nikolaeva EV, Poplavnoi AS (2015) Russ Phys J 58:574-582

104. Pound BG, Macdonald DD, Tomlinson JW (1980) Electrochim Acta 25:563-573

105. Grdeń M (2014) J Electroanal Chem 713:47-57

106. Barral G, Njanjo-Eyoke F, Maximovitch S (1995) Electrochim Acta 40:2815-2828

107. Bard AJ (1982) J Phys Chem 86:172-177

108. Seebauer EG, Kratzer MC (2009) Charged semiconductor defects: structure, thermodynamics and diffusion. Springer, London

109. Peter LM (1990) Chem Rev 90:753-769

110. Boukamp BA (1995) J Electrochem Soc 142:1885-1894

111. Boukamp BA, Macdonald JR (1994) Solid State Ionics 74:85-101

112. Agarwal P, Orazem ME, Garcia-Rubio LH (1992) J Electrochem Soc 139:1917-1927

113. Hirschorn B, Orazem ME, Tribollet B, Vivier V, Frateur I, Musiani M (2010) J Electrochem Soc 157:C452-C457

114. Bockris JO'M, Kham SUM (1993) Surface electrochemistry. A molecular level approach. Plenum Press, New York

115. Debiemme-Chouvy C, Cachet H (2008) J Phys Chem C 112: 18183-18188 